\title{
Những nhân tố ảnh hưởng đến tình trạng nghèo đa chiều của Việt Nam
}

\section{Factors affecting multi-dimensional poverty in Vietnam}

\author{
Lê Thị Thanh Loan ${ }^{1 *}$, Nguyễn Thanh Bình ${ }^{2}$ \\ ${ }^{1}$ Trường Đại học Mở Thành phố Hồ Chí Minh, Việt Nam \\ ${ }^{2}$ Cục Thống kê Thành phố Hồ Chí Minh, Việt Nam \\ *Tác giả liên hệ, Email: thanhloanle@gmail.com
}

THÔNG TIN

DOI: $10.46223 / \mathrm{HCMCOUJS.}$

econ.vi.13.3.1509.2018

Ngày nhận: 12/06/2018

Ngày nhận lại: 04/07/2018

Duyệt đăng: 10/07/2018

Tù khóa:

khảo sát mức sống dân cư, nghèo đa chiều, nghèo

\section{TÓM TÁT}

Mục tiêu của nghiên cứu là đo lường nghèo theo cách tiếp cận nghèo đa chiều để tính toán các chỉ số về nghèo đa chiều của Việt Nam và các vùng kinh tế của Việt Nam. Qua đó, phân tích và đánh giá thực trạng nghèo đa chiều của Việt Nam và các vùng kinh tế năm 2014, phân tích các yếu tố ảnh hưởng đến khả năng một hộ gia đình rơi vào tình trạng nghèo đa chiều ở Việt Nam. Nhóm tác giả đã sử dụng dữ liệu chéo, nguồn dữ liệu thứ cấp từ kết quả khảo sát Mức sống Hộ gia đình Việt Nam (VHLSS) năm 2014 của Tổng cục Thống kê để tính toán và đánh giá thực trạng nghèo đa chiều. Ngoài ra, mô hình hồi quy xác suất với biến nhị phân (Binary Logistic/Binary Logit) được sử dụng để xác định mối quan hệ và lượng hóa mức độ ảnh hưởng của các yếu tố nhân khẩu học và các yếu tố kinh tế - xã hội đến xác suất một hộ là nghèo đa chiều. Từ kết quả nghiên cứu, các khuyến nghị, hàm ý chính sách được đưa ra nhằm giảm nghèo đa chiều, giảm thiếu hụt từng chiều nghèo của Việt Nam và các vùng kinh tế.

\begin{abstract}
The objective of the study was to measure poverty in a multidimensional poverty approach to measure multi-dimensional poverty indicators in Vietnam and the economic regions of Vietnam. Thereby, it attempts to analyze and assess the multidimensional poverty in Vietnam and the economic regions in 2014. The study also analyzes the factors that affect the ability of a household that falls into multi-dimensional poverty in Viet Nam. The authors used cross-sectional data from the Vietnam Household Living Standard Survey (VHLSS) in 2014 results of the General Statistics Office to calculate and assess the multidimensional poverty status. In addition, the binary logistic model
\end{abstract}


Keywords:

living standard survey, multidimensional poverty, poverty

is used to determine the relationship and quantify the influence of demographic factors and socio-economic factors on the probability of one household of multi-dimensional poverty. From the research results, recommendations and policy implications are introduced to reduce multi-dimensional poverty and the depreciation of each poverty dimension in Vietnam and the economic regions.

\section{Giới thiệu}

Nghèo từ lâu đã được ghi nhận có tính chất đa chiều về bản chất nhưng cũng có nhiều tranh luận kéo dài về khả năng đo lường nghèo đa chiều và giá trị của việc kết hợp các chỉ tiêu khác biệt của thiếu hụt với chỉ tiêu nghèo thu nhập. Những tranh luận này đã thay đổi đáng kể vào năm 2007 khi ấn phẩm về phương pháp đo lường nghèo đa chiều dựa trên tính toán của Alkire và Foster. Phương pháp tiếp cận này đã có sức lôi cuốn trong phạm vi chính sách và thúc đẩy việc triển khai hệ thống đo lường nghèo đa chiều trên toàn cầu.

Năm 2010, Chỉ số nghèo đa chiều toàn cầu được phát triển bởi Chương trình Phát triển Liên Hợp Quốc (UNDP) và Tổ chức Sáng kiến Phát triển con người và nghèo đói Oxford (OPHI) đã xuất bản trong Báo cáo Phát triển con người năm 2010, và từ năm 2010 đến nay chỉ số này được thực hiện hàng năm.

Nhận định đây là phương pháp phù hợp trong việc giảm nghèo bền vững, Việt Nam đã nhanh chóng tiếp cận nghiên cứu phương pháp nghèo đa chiều, và Việt Nam là quốc gia thứ 20 tham gia vào Mạng lưới nghèo đa chiều toàn cầu vào tháng 8/2013 - The Global Multidimensional Poverty Peer Network (Global MPPN).

Đo lường nghèo theo phương pháp đa chiều là phương pháp tiếp cận mới, khi áp dụng phương pháp nghèo đa chiều thì chính sách, giải pháp giảm nghèo, giảm các chiều thiếu hụt của người dân và đối tượng người thụ hưởng có thay đổi, do đó việc đánh giá mức độ nghèo, mức độ thiếu hụt theo chuẩn nghèo tiếp cận đa chiều mới ban hành trên phạm vi cả nước và theo vùng kinh tế là cần thiết để phục vụ cho thiết kế chính sách giảm nghèo bền vững của quốc gia nói chung và cấp vùng kinh tế nói riêng. Mặt khác, các nghiên cứu về nghèo đa chiều trước đây chưa nghiên cứu trên phạm vi vùng kinh tế nên việc thực hiện đề tài này là cần thiết.

\section{Cơ sở lý thuyết và mô hình nghiên cứu}

\subsection{Khái niệm về nghèo đa chiều}

Nghèo được định nghĩa dựa vào hoàn cảnh xã hội của cá nhân, nghèo không chỉ đơn giản là mức thu nhập thấp mà còn thiếu hụt trong việc tiếp cận dịch vụ, như giáo dục, văn hóa, thuốc men, không chỉ thiếu tiền mặt, thiếu những điều kiện tốt hơn cho cuộc sống mà còn thiếu thể chế kinh tế thị trường hiệu quả, trong đó có các thị trường đất đai, vốn và lao động cũng như các thể chế nhà nước được cải thiện có trách nhiệm giải trình và vận hành trong khuôn khổ pháp lý minh bạch cũng như một môi trường kinh doanh thuận lợi. Nghèo còn là tình trạng đe dọa bị mất những phẩm chất quý giá, đó là lòng tin và lòng tự trọng. 
Theo Amartya Sen, người đoạt giải thưởng Nobel về kinh tế, cho rằng để sinh tồn thì con người cần có những nhu cầu tối thiểu về vật chất và tinh thần, nếu thiếu những nhu cầu tối thiểu này thì con người bị coi là sống trong nghèo khổ.

Để đánh giá tình trạng nghèo của hộ gia đình một cách toàn diện, khi nghiên cứu vấn đề nghèo của hộ gia đình cần được xem xét và phân tích theo các chỉ tiêu khác nhau, do đó, ngoài các phương pháp nghiên cứu truyền thống, việc đánh giá mức độ nghèo của hộ gia đình không chỉ dựa trên thu nhập hay chi tiêu, mà cần đánh giá mức độ "nghèo đa chiều" qua khía cạnh xã hội của đời sống dân cư với những thiếu hụt mà họ có thể phải gánh chịu như an sinh xã hội, giáo dục, y tế, nhà ở, hoạt động xã hội và an ninh.

Phương pháp Alkire và Foster $(\mathrm{AF})$, xác định người nghèo bằng cách xem xét nhiều khía cạnh họ đang gặp vấn đề và kết hợp lại từ tất cả người nghèo trong xã hội để đạt được một chỉ số nghèo đa chiều có thể so sánh giữa các vùng và so sánh theo thời gian. Chỉ số này đã được các nhà khoa học và các tổ chức trên thế giới nghiên cứu và sử dụng như là một công cụ để xác định hộ nghèo và trên cơ sở đó đề xuất giải pháp giảm nghèo.

\subsection{Co' sở xây dụng mô hình nghiên cúu}

Ở Anh, (Betti, D’Agostino, \& Neri, 2002) đã phân tích các nhân tố xã hội, nhân khẩu ảnh hưởng đến nghèo đói theo hai cách đo lường (nghèo thu nhập/nghèo chi tiêu và nghèo đa chiều - gồm tiện nghi trong gia đình, khả năng mua được hàng hóa lâu bền, điều kiện nhà ở, ...) dựa trên bộ dữ liệu bảng Khảo sát hộ gia đình Anh từ năm 1991 đến 1997. Trong mô hình, biến phụ thuộc dạng logit của $\mathrm{I}^{\mathrm{FS}}$ it là chỉ số nghèo đa chiều của hộ thứ i tại thời điểm $\mathrm{t}$, được đo lường bằng tổng có trọng số thứ bậc thiếu hụt tương đối của mỗi chỉ báo nghèo. Các biến giải thích trong mô hình gồm biến chỉ báo thời gian và những biến thể hiện đặc điểm của hộ: Giới tính; Tuổi và Bình phương Tuổi của chủ hộ; 2 biến giả về đặc điểm nghề nghiệp; 4 biến giả thể hiện trình độ hoc vấn của chủ hộ theo từng cấp độ; 1 biến giả thể hiện tình trạng hôn nhân. Ngoài ra, 2 biến giả thể hiện vùng địa lý, 2 biến thể hiện quy mô hộ gia đình. Tất cả các biến đều phụ thuộc thời gian và các tham số được ước lượng bởi Marginal Maximum Likelihood. Kết quả cho thấy, trừ biến JBSTA2 (thất nghiệp), các biến còn lại đều ảnh hưởng đến chỉ số nghèo đa chiều một cách có ý nghĩa thống kê.

Ở châu Âu, (Dewilde, 2008) thực hiện một nghiên cứu với mục tiêu tìm hiểu mức độ khác biệt giữa các quốc gia về nghèo đa chiều dưới ảnh hưởng của sự khác biệt giữa đặc điểm của cá nhân/hộ gia đình chứ không phải các yếu tố thể chế và sự phát triển kinh tế. Phân tích này dựa trên dữ liệu 10 nước châu Âu trong bảng dữ liệu Hộ gia đình Cộng đồng châu Âu (ECHP - wave 8,2011), với mẫu được hạn chế ở nhóm dân số dưới 65 tuổi. Trong nghiên cứu này, nghèo đa chiều được đo lường thông qua 10 chỉ báo trên 3 chiều: nhà ở, sự khốn đốn tài chính (trả nợ vay) và sự giới hạn về nguồn tài chính (khả năng chi tiêu). Nghiên cứu này sử dụng mô hình hồi quy Binary Logit để ước lượng ảnh hưởng của các nhân tố vi mô và vĩ mô đến rủi ro nghèo của hộ gia đình. Xét ở góc độ vi mô, các biến độc lập gồm những biến về đặc điểm nhân khẩu học như: Tuổi, Kiểu hộ gia đình, Có từ 3 con trở lên hay không; những biến về tình trạng kinh tế - xã hội của chủ hộ: Trình độ học vấn, Tầng lớp xã hội, Tính ổn định của công việc, Nguồn thu nhập chính (biến trễ t-1). Ngoài ra, mô hình còn bao gồm một số biến ghi nhận thông tin dọc của chủ hộ như số năm thất nghiệp và số năm trong gia đình chỉ có cha mẹ, và 
biến quốc gia. Các tham số của mô hình này được ước lượng bằng Maximum Likelihood. Kết quả ước lượng cho thấy, ngoại trừ biến số năm trong gia đình chỉ có cha mẹ, các biến còn lại đều có ý nghĩa thống kê ở mức $1 \%$.

Ở Cameroon, (Ningaye, Ndjanyou, \& Saakou, 2011) sử dụng bộ dữ liệu khảo sát ECAM II của Viện Thống kê Cameroon năm 2001 để đánh giá về thực trạng nghèo đa chiều, đơn chiều và các nhân tố ảnh hưởng đến nghèo đa chiều tại quốc gia này. Nhóm tác giả cũng sử dụng mô hình hồi quy logistic với biến nhị phân để phân tích tác động của các nhân tố ảnh hưởng đến nghèo đa chiều. Biến phụ thuộc $(\mathrm{Y})$ là biến nhị phân, thể hiện cho tình trạng nghèo đa chiều. Kết quả nghiên cứu cho thấy các biến quy mô của hộ gia đình và giới tính của chủ hộ không có ảnh hưởng có ý nghĩa thống kê đến xác suất hộ là nghèo đa chiều. Yếu tố có ảnh hưởng đáng kể đến rủi ro nghèo đa chiều được xác định là khu vực sinh sống.

Tại Indonesia, (Alkire et al., 2015) sử dụng mô hình hồi quy xác suất với biến nhị phân (Binary Logistics/Binary Logit) để phân tích dữ liệu Khảo sát Cuộc Sống Gia Đình Indonesia (Indonesian Family Life Survey (IFLS)) dựa trên kết quả đo lường nghèo đa chiều của Ballon và Apablaza (2012). Biến phụ thuộc $\mathrm{Y}_{\mathrm{i}}$ nhận giá trị bằng 1 nếu hộ nghèo đa chiều $\left(\mathrm{c}_{\mathrm{i}} \geq \mathrm{k}=33 \%\right)$, và bằng 0 nếu hộ không nghèo. Trong khuôn khổ mô hình GLM, biến phụ thuộc nhị phân này được ước lượng bằng phân phối Bernoulli và hàm logit, tương đương với mô hình hồi quy logit. Các biến giải thích trong mô hình này bao gồm những biến không được dùng trong các chỉ báo đo lường, cụ thể: Trình độ học vấn của chủ hộ, Giới tính của chủ hộ, Quy mô hộ gia đình, Khu vực cư trú của hộ, Tôn giáo, Kết quả hồi quy cho thấy, ngoại trừ biến tôn giáo, các biến còn lại đều có ý nghĩa thống kê ở mức 5\%.

Tại Việt Nam, khi nghiên cứu về nghèo thu nhập và nghèo đa chiều dựa trên bộ dữ liệu khảo sát hộ gia đình 2007, 2008 và 2010, (V. Q. Tran, Alkire, \& Klasen, 2015) đã chỉ ra một số nhân tố quan trọng ảnh hưởng đến khả năng nghèo đa chiều của hộ. Thứ nhất, mối quan hệ giữa quy mô hộ gia đình và nguy cơ nghèo đa chiều có dạng một hàm lồi. Thứ hai, kết quả nghiên cứu cho thấy tỷ lệ nghèo giảm đáng kể khi trình độ học vấn của chủ hộ tăng. Các hộ gia đình có học vấn càng thấp (không đi học hoặc chỉ học đến tiểu học) có nguy cơ nghèo cao hơn những hộ khác. Thứ ba, nghiên cứu cũng chỉ ra rằng có sự khác biệt về rủi ro nghèo đa chiều giữa những nhóm dân tộc khác nhau. Những nhóm dân tộc thiểu số thường sống ở những khu vực hạ tầng kém phát triển, do đó hạn chế trong tiếp cận giáo dục, y tế, chợ nên có rủi ro nghèo và cường độ nghèo cao hơn. Cuối cùng, tỷ lệ nghèo đa chiều có sự khác biệt giữa các tỉnh/thành phố.

\section{Mô hình phân tích các nhân tố ảnh hưởng đến nghèo đa chiều}

Các nghiên cứu trước hầu hết đều sử dụng mô hình hồi quy xác suất với biến nhị phân (Binary Logit/Binary Logistic) để phân tích các nhân tố ảnh hưởng đến nghèo đa chiều. Hơn nữa, (Alkire et al., 2015) đã nghiên cứu chi tiết về các kỹ thuật định lượng và đề xuất mô hình này như một khuôn khổ chung cho phân tích mối quan hệ giữa các biến số vi mô với nghèo đa chiều được đo lường theo phương pháp Alkire và Fosters (AF). Trong mô hình này, biến phụ thuộc thường là một biến nhị phân, có giá trị bằng 1 nếu hộ nghèo đa chiều (số điểm thiếu hụt $c_{i}$ lớn hơn hoặc bằng ngưỡng nghèo đa chiều $k$ ) và bằng 0 nếu hộ không nghèo. Để tránh trường hợp biến nội sinh, các biến độc lập trong mô hình cần được giới hạn ngoài những biến được 
dùng để tính các chỉ báo đo lường nghèo đa chiều, chẳng hạn như các biến nhân khẩu học, hay các biến về đặc điểm kinh tế - xã hội của hộ.

Do vậy, nghiên cứu cũng sẽ sử dụng mô hình hồi quy Binary Logistic để xác định các nhân tố ảnh hưởng đến khả năng hộ gia đình rơi vào tình trạng nghèo đa chiều ở Việt Nam năm 2014. Trong đó:

Biến phụ thuộc $\mathrm{Y}_{\mathrm{i}}$ thể hiện tình trạng nghèo đa chiều, nhận giá trị bằng 1 nếu hộ nghèo đa chiều và bằng 0 nếu hộ không nghèo đa chiều.

Gọi pi là xác suất có điều kiện phụ thuộc vào các biến giải thích để Yi nhận giá trị bằng 1 , tức xác suất để hộ thứ i là hộ nghèo đa chiều: $\mathrm{p}_{\mathrm{i}}=\mathrm{P}_{\mathrm{r}}\left(\mathrm{Y}_{\mathrm{i}}=1 \mid \mathrm{X}_{\mathrm{i}}\right)$

Mô hình Binary logistic được xác định như sau:

$$
\begin{aligned}
\operatorname{Ln}\left[\frac{P}{1-P}\right]=\eta_{\mathrm{i}} & =\alpha+\beta_{1} \mathrm{X}_{\mathrm{i} 1}+\beta_{2} \mathrm{X}_{\mathrm{i} 2}+\ldots . .+\beta_{\mathrm{k}} \mathrm{X}_{\mathrm{ik}} \\
\text { Hay: } \mathrm{p}_{\mathrm{i}}=\quad & \frac{1}{1+e^{-\eta_{i}}}=\frac{1}{1+e^{-\sum_{j=0}^{K} \beta_{j} x_{i j}}} .
\end{aligned}
$$

Dựa trên tham khảo kết quả của các nghiên cứu trước ở một số quốc gia khác nhau và tình hình các yếu tố nhân khẩu học, kinh tế-xã hội thực tế cũng như thông tin có sẵn trong dữ liệu khảo sát mức sống hộ gia đình Việt Nam năm 2014, các nhân tố có thể có ảnh hưởng đến rủi ro nghèo đa chiều của các hộ gia đình được chọn đưa vào mô hình như các biến độc lập bao gồm:

\section{Bảng 1}

Tổng hợp các biến độc lập trong mô hình nghiên cứu

\begin{tabular}{|l|l|c|}
\hline \multicolumn{1}{|c|}{ Tên biến độc lập } & \multicolumn{1}{|c|}{ Mô tả } & Dấu kỳ vọng (*) \\
\hline $\begin{array}{l}\text { Trình độ học vấn } \\
\text { của chủ hộ }\end{array}$ & Số năm đi học của chủ hộ & - \\
\hline $\begin{array}{l}\text { Trình độ chuyên } \\
\text { môn của chủ hộ }\end{array}$ & $\begin{array}{l}=1 \text { nếu đã qua đào tạo nghề nghiệp } \\
=0 \text { nếu chưa qua đào tạo nghề nghiệp }\end{array}$ & - \\
\hline $\begin{array}{l}\text { Giới tính của chủ } \\
\text { hộ }\end{array}$ & $\begin{array}{l}\text { = nếu là nữ } \\
=0 \text { nếu là nam }\end{array}$ & + \\
\hline Tổng số người & Quy mô của hộ gia đình & + \\
\hline $\begin{array}{l}\text { Khu vực cư trú của } \\
\text { hộ }\end{array}$ & $\begin{array}{l}\text { = 1 nếu sống ở thành thị } \\
=0 \text { nếu sống ở nông thôn }\end{array}$ & - \\
\hline Tuối & Tuổi của chủ hộ & - \\
\hline $\begin{array}{l}\text { Việc làm của chủ } \\
\text { hộ }\end{array}$ & $\begin{array}{l}\text { 1: Làm việc hưởng lương/ Tự sản xuất kinh } \\
\text { doanh } \\
\text { 0: Không làm việc/ thất nghiệp }\end{array}$ & - \\
\hline
\end{tabular}




\begin{tabular}{|l|l|c|}
\hline \multicolumn{1}{|c|}{ Tên biến độc lập } & \multicolumn{1}{|c|}{ Mô tả } & Dấu kỳ vọng (*) \\
\hline Dân tộc & $\begin{array}{l}\text { Dân tộc của chủ hộ, nhận giá trị là 1 nếu chủ } \\
\text { hộ dân tộc kinh, nhận giá trị 0 là dân tộc khác }\end{array}$ & - \\
\hline \multirow{2}{*}{ Vùng kinh tế } & $\begin{array}{l}\text { Cả nước chia ra 6 vùng kinh tế: } \\
\text { - Đồng bằng Sông Hồng } \\
\text { - Trung du và miền núi phía Bắc } \\
\text { - Bắc Trung Bộ và duyên hải Miền Trung } \\
- \text { Tây Nguyên } \\
\text { - Đông Nam bộ } \\
\text { - Đồng bằng sông Cửu Long } \\
\text { Vùng Đồng bằng sông Hồng được chọn làm } \\
\text { biến tham chiếu }\end{array}$ & + \\
\hline
\end{tabular}

Ghi chú: (*) Dấu (+) thể hiện đồng biến, dấu (-) thể hiện nghịch biến. Hộ có khả năng rơi vào nghèo đa chiều nhiều hơn (đồng biến) hoặc ít hơn (nghịch biến)

Nguồn: Kết quả phân tích dữ liệu của nhóm nghiên cứu

\section{Kết quả nghiên cứu}

\subsection{Chỉ số nghèo đa chiều (MPI)}

Áp dụng phương pháp nghèo đa chiều để đánh giá thực trạng nghèo của hộ gia đình Việt Nam, Chính phủ đã quyết định chọn 5 dịch vụ xã hội (Chính phủ, 2015) cơ bản mà người dân phải được tiếp cận đầy đủ là: giáo dục,y tế, nhà ở, điều kiện sống và tiếp cận thông tin với các chỉ số đo lường mức độ thiếu hụt các dịch vụ xã hội cơ bản (10 chỉ số) là trình độ giáo dục của người lớn, tình trạng đi học của trẻ em, tiếp cận các dịch vụ y tế, bảo hiểm y tế, chất lượng nhà ở, diện tích nhà ở bình quân đầu người, nguồn nước sinh hoạt, hố xí/nhà tiêu hợp vệ sinh, sử dụng dịch vụ viễn thông, tài sản phục vụ tiếp cận thông tin. chiều.

Chỉ số nghèo đa chiều (MPI) là chỉ số tổng hợp dùng để lượng hóa tình trạng nghèo đa

$$
\mathrm{MPI}=\mathrm{H} * \mathrm{~A}
$$

Trong đó:

- H là tỷ lệ (\%) hộ nghèo đa chiều, theo chuẩn hộ nghèo năm 2016-2020 hộ nghèo đa chiều là hộ thiếu hụt từ 3 chỉ số đo lường của 5 dịch vụ xã hội cơ bản trở lên;

- A là cường độ thiếu hụt, là phần trăm điểm thiếu hụt trung bình của các hộ nghèo. 5 chiều dịch vụ xã hội cơ bản được đo lường bằng 10 chỉ số, điểm thiếu hụt của mỗi chỉ số là 10 điểm, tổng điểm thiếu hụt là 100 điểm.

Tỷ lệ nghèo đa chiều $(\mathrm{H})$ của cả nước năm 2014 là 19,42\%, có nghĩa là 19,42\% số hộ của cả nước có điểm thiếu hụt các chiều xã hội từ 30 điểm trở lên hay thiếu hụt 3 chỉ số trở lên. Tỷ lệ nghèo đa chiều $(\mathrm{H})$ của khu vực nông thôn là $24,6 \%$ và dân tộc khác là $41 \%$, gần $1 / 4$ hộ nông thôn và $2 / 5$ hộ dân tộc khác thiếu hụt đa chiều. 
Cường độ nghèo đa chiều $(\mathrm{A})$ là $37 \%$, có nghĩa là số hộ nghèo đa chiều bị thiếu hụt trung bình $37 \%$ của 10 chỉ số đo lường thiếu hụt. Mức thiếu hụt này gần với ngưỡng thiếu hụt $30 \%$ (3 chỉ số), cường độ nghèo đa chiều của hộ gia đình thiếu hụt đa chiều không quá cao so với ngưỡng. Cường độ nghèo đa chiều của vùng Trung du và miền núi phía Bắc cao nhất: 40\%, Tây Nguyên 39\%, các vùng còn lại có cường độ nghèo trong khoảng $32 \%-36 \%$.

Theo công thức, $\mathrm{MPI}=\mathrm{H}^{*} \mathrm{~A}=7,18 \%$, có nghĩa là nếu $19,42 \%$ hộ nghèo đa chiều bị thiếu hụt tất cả 10 chỉ số đo lường thì MPI bằng 19,42\%, nhưng vì các hộ này chỉ thiếu hụt trung bình $37 \%$ của 10 chỉ số nên cả nước chỉ thiếu hụt $7,18 \%$ trong tổng số các thiếu hụt có thể xảy ra. Như vậy, tỷ lệ nghèo đa chiều đếm đầu $(\mathrm{H}) 19,42 \%$ đã được điều chỉnh bởi cường độ nghèo (A) 37\%.

Bảng 2 cho thấy chỉ số nghèo đa chiều của khu vực nông thôn là $9,16 \%$ cao hơn thành thị $(2,51 \%)$. Chỉ số nghèo đa chiều của dân tộc khác là $16,56 \%$ cao hơn dân tộc Kinh $(5,19 \%)$.

Vùng Đồng bằng sông Hồng và Đông Nam bộ có chỉ số nghèo đa chiều thấp nhất $(2,6 \%$ và $2,97 \%)$. Vùng Đồng bằng sông Cửu Long có chỉ số nghèo đa chiều cao nhất $(12,78 \%)$, tiếp đó là Tây Nguyên $(11,61 \%)$ và vùng Trung du và miền núi phía Bắc $(10,64 \%)$. Vùng Bắc Trung bộ và duyên hải miền Trung có chỉ số nghèo đa chiều ở khoảng giữa $(4,59 \%)$ của các vùng có chỉ số nghèo đa chiều cao nhất và thấp nhất.

\section{Bảng 2}

MPI, $\mathrm{H}$ và $\mathrm{A}$ theo khu vực, dân tộc và vùng kinh tế (\%)

\begin{tabular}{|c|c|c|c|}
\hline & $\mathbf{H}$ & $\mathbf{A}$ & MPI \\
\hline Chung & 19,42 & 37,00 & 7,18 \\
\hline \multicolumn{4}{|l|}{ Theo khu vuec } \\
\hline Thành thị & 7,16 & 35,00 & 2,51 \\
\hline Nông thôn & 24,6 & 37,00 & 9,16 \\
\hline \multicolumn{4}{|l|}{ Theo dân tộc của chủ hộ } \\
\hline Dân tộc Kinh & 14,85 & 35,00 & 5,19 \\
\hline Dân tộc khác & 40,90 & 40,00 & 16,56 \\
\hline \multicolumn{4}{|l|}{ Theo vùng kinh tế } \\
\hline Đồng bằng sông Hồng & 8,08 & 32,00 & 2,6 \\
\hline Trung du và miền núi phía Bắc & 26,53 & 40,00 & 10,64 \\
\hline Bắc Trung Bộ và duyên hải miền Trung & 12,92 & 36,00 & 4,59 \\
\hline Tây Nguyên & 30,11 & 39,00 & 11,61 \\
\hline Đông Nam Bộ & 8,56 & 35,00 & 2,97 \\
\hline Đồng bằng sông Cửu Long & 34,96 & 37,00 & 12,78 \\
\hline
\end{tabular}

Nguồn: Kết quả tính toán từ dữ liệu VHLSS 2014

\subsection{Các yếu tố ảnh hưởng đến tình trạng nghèo đa chiều}

Xác định các yếu tố ảnh hưởng đến nghèo đa chiều theo mô hình hồi quy logistic đề xuất ở trên, kết quả mô hình như sau: 


\section{Bảng 3}

Kết quả mô hình hồi quy logistic

Biến phụ thuộc: Hộ nghèo đa chiều=1; Hộ không nghèo đa chiều=0

\begin{tabular}{|c|c|c|c|c|c|c|}
\hline & \multirow[b]{2}{*}{$\mathbf{B}$} & \multirow[b]{2}{*}{ S.E. } & \multirow[b]{2}{*}{ Sig. } & \multirow[b]{2}{*}{$\operatorname{Exp}(B)$} & \multicolumn{2}{|c|}{$\begin{array}{c}\text { 95\% C.I.for } \\
\operatorname{EXP(B)} \\
\end{array}$} \\
\hline & & & & & Lower & Upper \\
\hline Số năm đi học &,$- 086 * * *$ & ,008 & ,000 & ,918 & ,904 & 4.932 \\
\hline Trình độ chuyên môn &,$- 951 * * *$ & ,068 & ,000 & ,386 & ,338 & .441 \\
\hline Giới tính chủ hộ & ,090 &, 075 & ,228 & 1,094 & ,945 & 1.267 \\
\hline Tổng số người &, 015 & 019 &, 430 & 1,015 & ,978 & 1.055 \\
\hline Khu vực & $-1,009 * * *$ & 087 &, 000 & ,365 &, 307 & 7.432 \\
\hline Tuổi của chủ hộ &,$- 025 * * *$ & ,003 &, 000 & ,975 & ,970 & .980 \\
\hline Việc làm của chủ hộ &,$- 228 * *$ &, 105 &, 030 & ,796 & ,648 & .978 \\
\hline Dân tộc Kinh &,$- 916 * * *$ & ,084 &, 000 & ,400 & ,339 & .472 \\
\hline Trung du và miền núi phía Bắc &, $327 * * *$ &, 121 & ,007 & 1,387 & 1,094 & 1.758 \\
\hline Bắc Trung Bộ và DH miền Trung &, 131 &, 111 & ,237 & 1,140 & ,917 & 1.417 \\
\hline Tây Nguyên &, $887 * * *$ & ,135 &, 000 & 2,427 & 1,864 & 3.161 \\
\hline Đông Nam bộ &,- 158 &, 142 & ,267 &, 854 & ,646 & 1.128 \\
\hline Đồng bằng sông Cửu Long & $1,353 * * *$ &, 101 &, 000 & 3,868 & 3,171 & 4.717 \\
\hline Hằng số & 1,203 & ,242 &, 000 & 3,330 & & \\
\hline
\end{tabular}

Ghi chú: *** có ý nghĩa thống kê ở mức $1 \%$, ** có ý nghĩa thống kê ở mức $5 \%$

Nguồn: Kết quả phân tích dữ liệu của nhóm nghiên cứu

4 biến độc lập: giới tính của chủ hộ, tổng số người trong hộ, vùng Bắc trung bộ và duyên hải miền Trung và vùng Đông Nam bộ chưa đủ chứng cứ để kết luận các biến này có ảnh hưởng đến hộ nghèo đa chiều. Biến việc làm có ý nghĩa thống kê ở mức $\alpha=5 \%$, các biến độc lập còn lại trong mô hình đều có ý nghĩa thống kê với chứng cứ rất mạnh: $\alpha=1 \%$. đầu.

Hệ số b của các biến độc lập trong mô hình đều mang dấu phù hợp với giả thuyết ban

\section{Bảng 4}

Omnibus tests of model coefficients

\begin{tabular}{|l|l|r|r|r|}
\hline \multicolumn{2}{|c|}{} & \multicolumn{1}{|c|}{ Chi-square } & df & \multicolumn{1}{c|}{ Sig. } \\
\hline \multirow{3}{*}{ Step 1 } & Step & 1910,737 & 13 &, 000 \\
\cline { 2 - 5 } & Block & 1910,737 & 13 &, 000 \\
\cline { 2 - 5 } & Model & 1910,737 & 13 &, 000 \\
\hline
\end{tabular}

Mô hình có ý nghĩa thống kê chung với sig. $=0,000<\alpha=1 \%$

Nguồn: Kết quả phân tích dữ liệu của nhóm nghiên cứu 


\section{Bảng 5}

Model summary

\begin{tabular}{|c|c|c|c|}
\hline Step & -2 Log likelihood & Cox \& Snell R Square & Nagelkerke R Square \\
\hline 1 & $7347,568^{\mathrm{a}}$ &, 184 &, 294 \\
\hline
\end{tabular}

a. Estimation terminated at iteration number 6 because parameter estimates changed by less than .001 Nguồn: Kết quả phân tích dữ liệu của nhóm nghiên cứu

Theo Cox \& Snell R Square, các biến độc lập trong mô hình giải thích được 18,4\% xác suất rơi vào nghèo đa chiều của hộ và theo Nagelkerke $\mathrm{R}$ Square các biến độc lập trong mô hình giải thích được 29,4\% xác suất rơi vào nghèo đa chiều của hộ.

\section{Bảng 6}

Ước lượng xác suất nghèo đa chiều theo tác động biên của từng yếu tố

\begin{tabular}{|c|c|c|c|c|c|}
\hline \multirow[b]{2}{*}{ Các biến độc lập } & \multirow{2}{*}{$\begin{array}{c}\text { Hệ số } \\
\text { hồi quy } \\
\text { B }\end{array}$} & \multirow{2}{*}{$\begin{array}{l}\text { Hệ số tác } \\
\text { động biên } \\
\operatorname{Exp}(\mathbf{B})\end{array}$} & \multicolumn{3}{|c|}{$\begin{array}{c}\text { Xác suất nghèo đa chiều } \\
\text { (\%) khi biến độc lập thay } \\
\text { đổi } 1 \text { đơn vị và khi xác } \\
\text { suất ban đầu là: }\end{array}$} \\
\hline & & & $5 \%$ & $10 \%$ & $15 \%$ \\
\hline Số năm đi học &,- 086 & ,918 & 4,61 & 9,25 & 13,94 \\
\hline Trình độ chuyên môn &,- 951 & ,386 & 1,99 & 4,12 & 6,38 \\
\hline Khu vực & $-1,009$ & ,365 & 1,88 & 3,89 & 6,04 \\
\hline Tuổi &,- 025 & ,975 & 4,88 & 9,78 & 14,68 \\
\hline Việc làm của chủ hộ &,- 228 & ,796 & 4,02 & 8,13 & 12,32 \\
\hline Dân tộc Kinh &,- 916 & ,400 & 2,06 & 4,26 & 6,60 \\
\hline Trung du và miền núi phía Bắc &, 327 & 1,387 & 6,80 & 13,35 & 19,66 \\
\hline Tây Nguyên &, 887 & 2,427 & 11,33 & 21,24 & 29,99 \\
\hline Đồng bằng sông Cửu Long & 1,353 & 3,868 & 16,91 & 30,06 & 40,56 \\
\hline
\end{tabular}

Nguồn: Kết quả phân tích dữ liệu của nhóm nghiên cứu

Từ kết quả hồi quy và kết quả tính toán xác suất nghèo đa chiều theo mức độ tác động từng yếu tố, nhận định về các biến độc lập tác động đến biến phụ thuộc nghèo đa chiều như sau:

Số năm đi học của chủ hộ: Biến số năm đi học của chủ hộ có ý nghĩa thống kê ở mức $1 \%$. Hệ số hồi quy $\mathrm{B}$ của biến mang dấu âm (-), tức quan hệ nghịch biến với biến hộ nghèo đa chiều, điều này phù hợp với kỳ vọng ban đầu. Khi số năm đi học của chủ hộ tăng lên 1 năm, với các biến độc lập khác trong mô hình không đổi, trong trường hợp xác suất nghèo đa chiều cho trước là $5 \%$ thì xác suất nghèo đa chiều của hộ sẽ là $4,61 \%$, thấp hơn xác suất cho trước.

Trình độ chuyên môn của chủ hộ: Biến trình độ chuyên môn chủ hộ có ý nghĩa thống kê ở mức $1 \%$. Hệ số hồi quy $\mathrm{B}$ của biến mang dấu âm (-), tức quan hệ nghịch biến với biến hộ nghèo đa chiều, điều này phù hợp với kỳ vọng ban đầu. Khi chủ hộ đã qua đào tạo nghề nghiệp, 
với các biến độc lập khác trong mô hình không đổi, trong trường hợp xác suất nghèo đa chiều cho trước là $5 \%$ thì xác suất nghèo đa chiều của hộ sẽ là $1,99 \%$, thấp hơn xác suất cho trước.

Khu vực cư trú của hộ: Biến khu vực cư trú của chủ hộ có ý nghĩa thống kê ở mức $1 \%$. Hệ số hồi quy $\mathrm{B}$ của biến mang dấu âm (-), tức quan hệ nghịch biến với biến hộ nghèo đa chiều, điều này phù hợp với kỳ vọng ban đầu. Nếu hộ ở khu vực thành thị, với các biến độc lập khác trong mô hình không đổi, trong trường hợp xác suất nghèo đa chiều cho trước là $5 \%$ thì xác suất nghèo đa chiều của hộ thành thị sẽ là $1,88 \%$, thấp hơn xác suất cho trước.

Tuổi: Biến tuổi của chủ hộ có ý nghĩa thống kê ở mức $1 \%$. Hệ số hồi quy $\mathrm{B}$ của biến mang dấu âm (-), tức quan hệ nghịch biến với biến hộ nghèo đa chiều, điều này phù hợp với kỳ vọng ban đầu. Khi tuổi của chủ hộ tăng lên 1 năm, với các biến độc lập khác trong mô hình không đổi, trong trường hợp xác suất nghèo đa chiều cho trước là $5 \%$ thì xác suất nghèo đa chiều của hộ sẽ là $4,88 \%$, thấp hơn xác suất cho trước.

Việc làm của chủ hộ: Biến việc làm của chủ hộ có ý nghĩa thống kê ở mức 5\%. Hệ số hồi quy $\mathrm{B}$ của biến mang dấu âm (-), tức quan hệ nghịch biến với biến hộ nghèo đa chiều, điều này phù hợp với kỳ vọng ban đầu. Khi chủ hộ là người làm việc hưởng lương hay tự sản xuất kinh doanh, với các biến độc lập khác trong mô hình không đổi, trong trường hợp xác suất nghèo đa chiều cho trước là $5 \%$ thì xác suất nghèo đa chiều của hộ sẽ là $4,02 \%$, thấp hơn xác suất cho trước.

Dân tộc: Biến dân tộc của chủ hộ có ý nghĩa thống kê ở mức 1\%. Hệ số hồi quy B của biến mang dấu âm (-), tức quan hệ nghịch biến với biến hộ nghèo đa chiều, điều này phù hợp với kỳ vọng ban đầu. Khi chủ hộ là dân tộc Kinh, với các biến độc lập khác trong mô hình không đổi, trong trường hợp xác suất nghèo đa chiều cho trước là $5 \%$ thì xác suất nghèo đa chiều của hộ sẽ là 2,06\%, thấp hơn xác suất cho trước.

Vùng kinh tế: Các biến vùng Trung du và miền núi phía Bắc, Tây Nguyên và Đồng bằng sông Cửu Long đều có ý nghĩa thống kê ở mức $1 \%$. Hệ số hồi quy $\mathrm{B}$ của các biến vùng này đều mang dấu dương $(+)$, tức quan hệ đồng biến với biến hộ nghèo đa chiều, điều này phù hợp với kỳ vọng ban đầu, người dân ở các vùng này sẽ có xác suất là hộ nghèo đa chiều cao hơn các vùng còn lại. Với các biến độc lập khác trong mô hình không đổi, trong trường hợp xác suất nghèo đa chiều cho trước là $5 \%$ thì nếu hộ ở vùng Trung du và miền núi phía Bắc sẽ có xác suất nghèo đa chiều là $6,8 \%$; hộ ở Tây Nguyên sẽ có xác suất nghèo đa chiều là $11,33 \%$; và hộ ở Đồng bằng song Cửu Long có xác suất nghèo đa chiều là $16,91 \%$ cao hơn xác suất cho trước.

\section{Kết luận và khuyến nghị}

Đánh giá nghèo theo phương pháp đơn chiều, dựa trên yếu tố thu nhập hoặc chi tiêu là phương pháp được thế giới trong đó có Việt Nam áp dụng trong thời gian dài. Tuy nhiên việc đánh giá nghèo theo phương pháp đơn chiều đã thể hiện những hạn chế khi mà chỉ tiêu thu nhập hay chi tiêu không phản ánh hết sự thiếu hụt trong mọi khía cạnh của cuộc sống.

Phương pháp nghèo đa chiều theo Alkire và Foster là phương pháp được các quốc gia trên thế giới áp dụng hiện nay. Từ năm 2010, chỉ số nghèo đa chiều toàn cầu MPI tính cho thế giới và các quốc gia theo phương pháp Alkire Foster đã được đưa vào Báo cáo Phát triển Con 
người, là báo cáo thường niên của UNDP. Việt Nam thuộc nhóm các quốc gia sớm nghiên cứu và áp dụng phương pháp nghèo đa chiều vào công tác giảm nghèo của quốc gia.

Các yếu tố ảnh hưởng đến nghèo đa chiều có ý nghĩa thống kê bao gồm: số năm đi học của chủ hộ, trình độ chuyên môn của chủ hộ, khu vực cư trú, tuổi, việc làm, dân tộc và các vùng Trung du và miền núi phía Bắc, Tây Nguyên và Đồng bằng sông Cửu Long là gợi ý cho các khuyến nghị chính sách giảm nghèo đa chiều.

Các yếu tố ảnh hưởng đến nghèo đa chiều được kiểm định qua mô hình hồi quy logistic cũng nhất quán với các đặc điểm thiếu hụt thông qua thống kê mô tả là có sự khác biệt thiếu hụt đa chiều ở hộ gia đình thành thị - nông thôn, dân tộc kinh - dân tộc khác và các vùng kinh tế. Do đó, giải pháp giảm nghèo đa chiều cần chú trọng ở khu vực nông thôn, dân tộc khác và các vùng Đồng bằng sông Cửu Long, Tây Nguyên và vùng Trung du và miền núi phía Bắc.

Yếu tố trình độ văn hóa và trình độ chuyên môn, việc làm của chủ hộ đều ảnh hưởng có ý nghĩa đến thiếu hụt đa chiều của hộ, đặc biệt yếu tố trình độ chuyên môn có tác dụng giảm xác suất rơi vào nghèo đa chiều đáng kể.

Giải pháp giảm nghèo đa chiều cần chú ý vào đào tạo nghề, nâng cao trình độ chuyên môn của người dân, của người lao động, quan tâm tạo việc làm cho người lao động là các yếu tố quan trọng, đảm bảo cuộc sống cũng như khả năng tiếp cận các dịch vụ xã hội cơ bản.

\section{Hạn chế của nghiên cứu}

Do không tiếp cận được dữ liệu Khảo sát mức sống hộ gia đình năm 2016 nên việc đánh giá thực trạng nghèo đa chiều của cả nước có hạn chế vì áp dụng chuẩn nghèo giai đoạn 20162020 nhưng tính trên dữ liệu 2014, mức độ tiếp cận các dịch vụ xã hội cơ bản của các hộ gia đình năm 2016 có thể khác so năm 2014: có thể tốt hơn hoặc kém hơn.

Do sử dụng dữ liệu thứ cấp cho nghiên cứu nên thông tin cho nghiên cứu cũng hạn chế chưa đầy đủ theo yêu cầu của nghiên cứu.

\section{Tài liệu tham khảo}

Alkire, S., \& Foster, J. E. (2007). Counting and multidimensional poverty measurement. Journal of Public Economics, 95(7/8), 476-487.

Alkire, S., Foster, J. E., Seth, S., Santos, M. E., Roche, J., \& Ballon, P. (2015). Some regression models for AF measures. In Multidimensional poverty measurement and analysis. Oxford, UK: University of Oxford.

Alkire, S., Foster, J. E., Seth, S., Santos, M. E., Roche, J., \& Ballon, P. (2015). The AlkireFoster counting methodology. In Multidimensional poverty measurement and analysis. Oxford, UK: University of Oxford.

Ballon, P., \& Apablaza, M. (2012). Multidimensional poverty dynamics in Indonesia. Paper presented at the Research Workshop on Dynamic Comparison between Multidimensional Poverty and Monetary Poverty, OPHI, University of Oxford, UK. 
Betti, G., D'Agostino, A., \& Neri, L. (2002). Panel regression models for measuring multidimensional poverty dynamics. Statistical Methods and Applications, 11(3), 359369.

Chính phủ. (2015). Quyết định 59/2015/QĐ-Ttg của Thủ tướng Chính phủ về viẹc ban hành chuẩn nghèo tiếp cận đa chiều áp dụng cho giai đoạn 2016-2020 [Decision 59/2015 / QD-Ttg of the Prime Minister on promulgating multidimensional poverty lines applicable for the period 2016-2020]. Retrieved February 15, 2018, from https://huvienphapluat.vn/van-ban/Van-hoa-Xa-hoi/Quyet-dinh-59-2015-QD-TTgchuan-ngheo-tiep-can-da-chieu-ap-dung-2016-2020-296044.aspx

Dewilde, C. (2008). Individual and institutional determinants of multidimensional poverty: A European comparison. Social Indicators Research: An International and Interdisciplinary Journal for Quality-of-Life Measurement, 86(2), 233-256.

Ningaye, P., Ndjanyou, L., \& Saakou, G. M. (2011). Multidimensional poverty in Cameroon: Determinants and spatial distribution. Retrieved April 1, 2018, from http://core.kmi.open.ac.uk/download/pdf/6476038.pdf.

Oxford Poverty and Human Development Initiative (OPHI). (2010). Research to reduce multidimensional poverty and advance welfare economics, building on the capability approach of Amartya Sen. Retrieved February 15, 2016, from http://www.ophi.org.uk/resources/ophi working-papers/

Tran, T. K., \& Nguyen, N. D. (2012). Quan hệ giũa sinh kế và tình trạng nghèo ở nông thôn Việt Nam [Relationship between livelihoods and poverty in rural Vietnam]. Retrieved April 2, 2018, from http://luanvan.net.vn/luan-van/de-tai-quan-he-giua-sinh-ke-va-tinhtrang-ngheo-o-nong-thon-viet-nam-63442/

Tran, V. Q., Alkire, S., \& Klasen, S. (2015). Static and dynamic disparities between monetary and research on economic inequality. Measurement of Poverty, Deprivation, and Economic Mobility, 23, 249-281.

United Nations Development Programme. (2010). Đánh giá nghèo đô thị ở Hà Nội và TP. Hồ Chi Minh [Assessment of Urban Poverty in Hanoi and Ho Chi Minh City]. Hanoi, Vietnam: NXB Thanh Niên.

United Nations Development Programme. (2010). Human development report 2010: The real wealth of nations: Pathways to human development. New York, NY: UNDP.

United Nations Development Programme. (2015). Phân tích nghèo đô thị tại Hà Nội và Thành phố Hồ Chí Minh, năm 2009 và 2012 [Urban poverty analysis in Hanoi and Ho Chi Minh City, 2009 and 2012]. Ho Chi Minh, Vietnam: NXB Hồng Đức. 